\title{
FINITE ELEMENT MODELING AND BENDING STRESS ANALYSIS OF NON STANDARD SPUR GEAR
}

\author{
G Mallesh ${ }^{1}$, Avinash $P^{2}$, Melvin Kumar $\mathbf{R}^{3}$, Sacchin $\mathbf{G}^{\mathbf{4}}$, Zayeem Khan ${ }^{5}$ \\ ${ }^{1}$ Associate Professor, Dept. of Mechanical Engineering, SJCE, Mysuru-570 006, Karnataka, India \\ ${ }^{2}$ Research Group, Dept. of Mechanical Engineering, SJCE, Mysuru-570 006, Karnataka, India \\ ${ }^{3}$ Research Group, Dept. of Mechanical Engineering, SJCE, Mysuru-570 006, Karnataka, India \\ ${ }^{4}$ Research Group, Dept. of Mechanical Engineering, SJCE, Mysuru-570 006, Karnataka, India \\ ${ }^{5}$ Research Group, Dept. of Mechanical Engineering, SJCE, Mysuru-570 006, Karnataka, India
}

\begin{abstract}
Gears are toothed wheels, transmitting power and motion from one shaft to another by means of successive engagement of teeth. Having a higher degree of reliability, compactness, high velocity ratio and finally able to transmit motion at a very low velocity, gears are gaining importance as the most efficient means for transmitting power. A gearing system is susceptible to problems such as interference, backlash and undercut. The contact portions of tooth profiles that are not conjugate is called interference. Furthermore due to interference and in the absence of undercut, the involute tip or face of the driven gear tends to dig out the non-involute flank of the driver. The response of a spur gear and its wear is an engineering problem that has not been completely overcome yet.
\end{abstract}

With the perspective of overcoming such defects and for increase the efficiency of gearing system, the use of a non-standard spur gear i.e., an asymmetric spur gear having different pressure angles for drive and coast side of the tooth comes into picture. This paper emphasis on the generation of an asymmetric spur gear tooth using modeling software and bending stress at the root of Asymmetric spur gear tooth is estimated by finite element analysis using ANSYS software and results were compared with the standard spur gear tooth.

Keywords: Asymmetric spur gear, Bending stress, Finite element method, Pressure angle ****

\section{INTRODUCTION}

The most common means for transmitting power in the modern mechanical engineering world is through the use of gears. Their size vary from the minnows used in the watches to the larger ones finding application in speed reducing units. They function as vital elements of main and ancillary mechanisms in machines. Toothed gears are used to change the speed and power ratio as well as direction between input and output. In ancient times, gears were produced using wood with cylindrical pegs for cogs while animal fat grease served as lubricant.

The metal gearing, it all started during the eighteenth century industrial revolution in Britain, followed by the early parts of nineteenth century during which science of gear design and manufacturing was extensively developed. Increasing demand for lighter automotive from customers, the aerospace and automobile industries now rely upon gears having increased strength, reliability and at the same time having lighter weight. Hence, during the recent times, the subject gear design is highly complicated and a comprehensive one. For a designer of modern times, it is important to remember that the main objective of a gear drive is to transmit higher power with comparatively smaller overall dimensions of the driving system, incurring minimum cost at the production stage, runs reasonably free of noise and vibration and requiring least maintenance.
Gears mainly suffer from fracture under bending stress, surface failure under internal stress etc. arising out of defects due to interference, backlash and undercut. In order to overcome these difficulties an asymmetric serves as a better choice over the conventional spur gear. An asymmetric spur gear is one with low pressure angle profile on drive side and high pressure angle profile on the coast side of the teeth. This modification in standard spur gear leads to the decrease the bending stress.

The purpose of the present work is to study the effect of gear tooth geometry on gear tooth stress. Accuracy of the results depends upon the development of geometrically correct tooth profile. Many methods have been developed to generate a symmetric spur gear tooth with standard cutters for different cutter parameters. Hence, it is required to develop gear profile using gear tooth parameters with the help of computer aided modeling software. Apart from load and tooth geometry the stresses in a gear tooth depends upon various other factors. For the determination of bending stress, a gear tooth is considered as a cantilever beam and thus they are referred as static stresses. Further, the static stresses are multiplied by a number of factors in order to compensate each of the other influences. In the year 1892, Wilfred Lewis made a path breaking discovery in the field of gear technology by formulating the basic equation for the estimation of bending stress in gear tooth. 
So far, several methods have been developed to estimate the tooth bending stress of symmetric involute gears. Two of them are introduced by ISO 6336 and DIN 3990. These standards are very much alike except for a few points and each of them is based upon the following hypotheses.

The critical section of the tooth is defined by the point of tangency with the root fillet of a line rotated $30^{\circ}$ from tooth centerline as shown in Figure.1.The compressive stress produced by the radial component of the tooth load can be neglected. Total tooth load acts at the tip of the tooth (only in DIN 3990/Method C and ISO 6336/TC60 Method C).

Since there are no established method for asymmetric gear tooth, the method given by Pedrero et al. [5] is used. The adaptation is based on the following considerations:

The maximum tooth bending stress occurs at the point of tangency with the root fillet of a line rotated $30^{\circ}$ from the tooth centerline on the drive side of asymmetric tooth as shown in Figure.2.

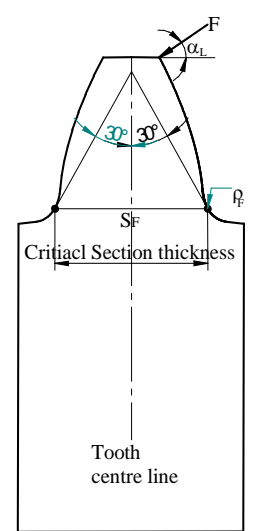

Fig-1: Symmetric tooth model for bending stress (DIN 3990)

The stress that takes a very important part in tooth root crack origination is maximum tensile stress $\sigma_{t}$ at the tooth root region. The tensile stress $\sigma_{t}$ at the root of the tooth is given by [11],

$\sigma_{\text {tmax }}=\frac{F_{t}}{b m} K_{z} K_{\lambda} K_{a}$

$K_{z}=3.56+4.59\left(\frac{1}{z_{1}}\right)+1.740$

$K_{\lambda}=\exp \left[\left\{2.5\left(\frac{1}{z_{1}}\right)-0.5\right\} \frac{\lambda}{\mathrm{m}}\right]$

$K_{a}=1.32-\left(1.82 \times 10^{-2} \phi+1.17 \times 10^{-4} \phi^{2}\right)$

$\sigma_{\text {tmax }}(\mathrm{MPa})$ maximum tensile stress, $F_{t}$ tangential tooth load, $b$ face width of the gear considered to be 10 times the module $m$, module, $K_{z}$ tooth number influence factor, $K_{\lambda}$ load position influence factor, $K_{a}$ pressure angle influence factor and $z_{1}$ number of teeth on pinion. The complex shape of the gear teeth makes it difficult to calculate the stresses accurately using the theory of elasticity. Based on the previous work, empirical expressions obtained from Photo elastic study [6] are reported to calculate the maximum stresses in the gear tooth. Rapid growth in the field of computer technology in the last few decades with respect to speed of computation and storage capacity has made it possible to compute the gear tooth stresses accurate enough to satisfy the design considerations. Further, some more empirical relations [7, 8, 9, and10] based on finite element study and experimental analyses are also reported in the literature. In the paper, 2D bending stress analyses was carried out by the finite element method (FEM). The results have been obtained by using the general purpose finite element analysis software ANSYS 14.5.

\section{LITERATURE REVIEW}

Gears being the most critical components in power transmission devices, the amount of available literature is vast. Attempts made by several researchers to address issues like bending and contact stress analysis, reliability and fatigue life, noise reduction, vibration analysis etc. has revealed that variations not only occur in the effects but also in the basic assumptions made.

The basic asymmetric tooth geometry was developed by Alexander L Kapelevich [11] in which the formulae and equations for gear and generating rack parameters were determined. In addition to this, the area of existence of asymmetric gears was studied. The test conducted on asymmetrical gears proved to be worthy as they show a considerable reduction in weight, size and vibration levels and increased loading capacity.

Using finite element method Gang Deng et al [12] worked on determining the tooth stress and bending stress for various combination of standard pressure angles $\left(20^{\circ} / 20^{\circ}\right.$, $20^{\circ} / 25^{\circ}, 20^{\circ} / 30^{\circ}$ and $20^{\circ} / 35^{\circ}$ ). The results obtained clarified that a larger standard pressure angle on the drive side of the tooth makes the tooth root stress decrease remarkably and bending stiffness increase without changing the load sharing ratio.

Alexander L Kapelevich et al [13] were able to put forward an alternative approach to conventional gear design called direct gear design which described a substitute method for the analysis and design of involute gears, to obtain a satisfactory performance corresponding to a particular application.

The studies conducted on the variation of bending stress and contact ratio depending on pressure angle by Kadir Cavdar, Fatih Karpat and Fatih C. Babalik [14] confirmed that, as the pressure angle on the drive side increases, the bending stress decreases and the bending load capacity increases. 


\section{MODELLING OF ASYMMETRIC SPUR GEAR TOOTH USING SOLID EDGE}

Generate gear tooth model using different parameters given in Table-1

Table-1: Gear tooth parameters

\begin{tabular}{|l|l|l|}
\hline 1 & $\mathrm{z}_{1}-$ No. of teeth on pinion & 20 \\
\hline 2 & $\mathrm{z}_{2}-$ No. of teeth on gear & 30 \\
\hline 3 & $\mathrm{x}_{1}-$ Profile shift on pinion & 0.0 \\
\hline 3 & $\mathrm{x}_{2}-$ Profile shift on Gear & 0.0 \\
\hline 4 & $\begin{array}{l}\Phi_{1}-\text { Pressure angle on coast } \\
\text { side }\end{array}$ & $20^{0}$ \\
\hline 5 & $\begin{array}{l}\Phi_{2}-\text { Pressure angle on drive } \\
\text { side, }\end{array}$ & $\begin{array}{l}20^{0}-35^{0} \text { by } 1^{0} \\
\text { increment }\end{array}$ \\
\hline 6 & $M_{n}-$ Module, mm & 4 \\
\hline 7 & Radius of rack cutter fillet, mm & 0.75 \\
\hline
\end{tabular}

Calculate the required parameters like pitch circle diameter, tooth thickness, addendum, clearance, dedendum and base circle diameter using standard gear formulae.

Pitch circle diameter $\mathrm{D}_{\mathrm{p}}=\mathrm{mz}$

Circular pitch $\mathrm{C}_{\mathrm{p}}=\pi \mathrm{m}$

Tooth thickness $\mathrm{T}=\frac{\pi m}{2}$

Addendum $=$ module

Addendum circle diameter $=\mathrm{D}_{\mathrm{p}}+2$ Addendum

Clearance $=\frac{\mathrm{Cp}}{20}$

Dedendum $=$ Addendum + clearance

Dedendum circle diameter $=\mathrm{D}_{\mathrm{p}}-2$ dedendum

Fillet radius $=\frac{\mathrm{Cp}}{8}$

Base circle diameter $=\mathrm{D}_{\mathrm{p}} \cos \theta$

Create pitch circle, addendum circle, dedendum circle and base circle diameters using create circle command, draw a line from the addendum circle to the base circle and divide the lines into three equal segments $12,23,34$ as shown in the figure (a).Draw a line from point 2 such that it is tangent to the base circle at point 5 then divide line 2-5 into four equal divisions as shown in the figure (d) with ' $R$ ' as the center ' $2 \mathrm{R}$ ' as the radius draw an arc between addendum and dedendum circle which passes through the point 2.Draw a fillet arc between dedendum circle and involute curve. Taking tooth thickness arc from ' 2 ' which cuts pitch circle diameter at ' $\mathrm{M}$ ' and repeat the procedure to get the involute curve on the other side.

Using array command entire gear model has been developed for symmetric and asymmetric spur gear tooth as shown in figure. 4

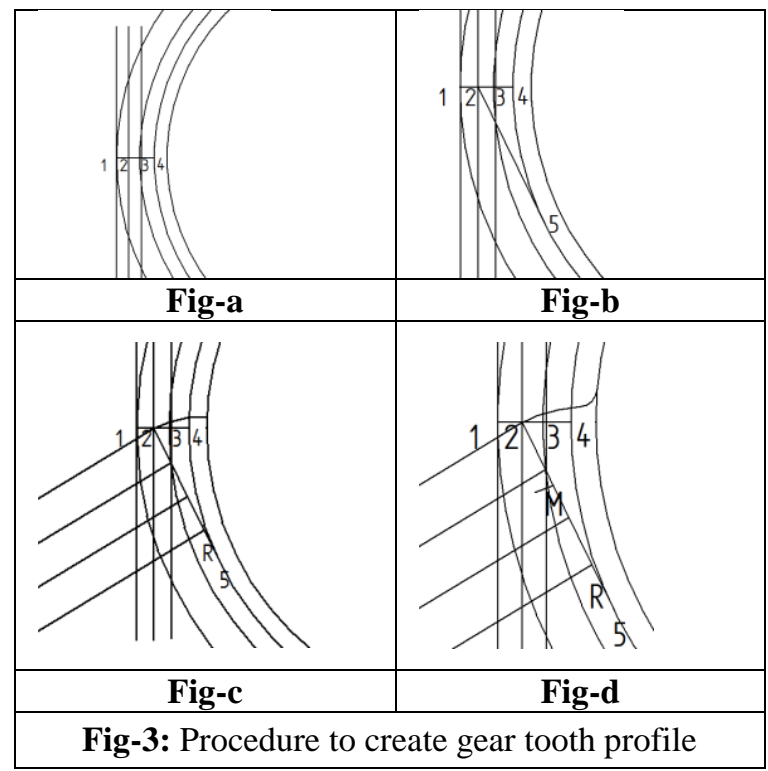

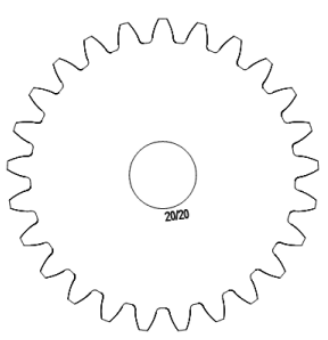

Full gear model of $20^{\circ} / 20^{\circ}$ pressure angle

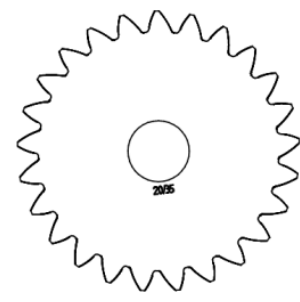

Full gear model of $20^{\circ} / 35^{0}$ pressure angle
Fig-4: Full gear tooth model for different pressure angles on drive side and coast side

Once the model has been created using solid edge software the model then saved as *.iges file format, which can be imported easily to the ANSYS environment to conduct bending stress analysis.

\section{FINITE ELEMENT ANALYSIS}

Finite element method is the one which is primarily used to determine the solution of a complex problem by replacing the former by a simpler one. As the former is replaced, by the latter in finding the solution, the method provides an approximate solution instead of an exact solution. The current mathematical tools are not sufficient to find exact solution for most of the practical problems.

The realistic use of finite element method for solving the problem involves preprocessing, analysis and post processing. The preprocessing involves the preparation of data such as nodal coordinates, element connectivity, boundary conditions, loading and material properties. The analysis stage involves stiffness generation, stiffness modification and solution of the equations resulting in the evaluation of nodal displacements and derived quantities such as stresses. The post processing deals with presentation of the results. A complete finite element analysis is a logical interaction of the three stages. 


\subsection{Load and Boundary Conditions}

As a major part of present investigation, a series of finite element analysis were carried out for different sets of symmetric and asymmetric spur gears subjected to a load at highest point of single tooth of contact (HPSTC) by considering the tangential component of the load. Gears are used to transmit power of $15 \mathrm{~kW}$ at $1000 \mathrm{rpm}$. The gear tooth is considered as a cantilever and is constrained at the rim (A-B-C-D). All the elements have two degrees of freedom while the elements at the rim are fixed. The meshed model subjected to displacement and force boundary conditions is as shown in Figure.5.

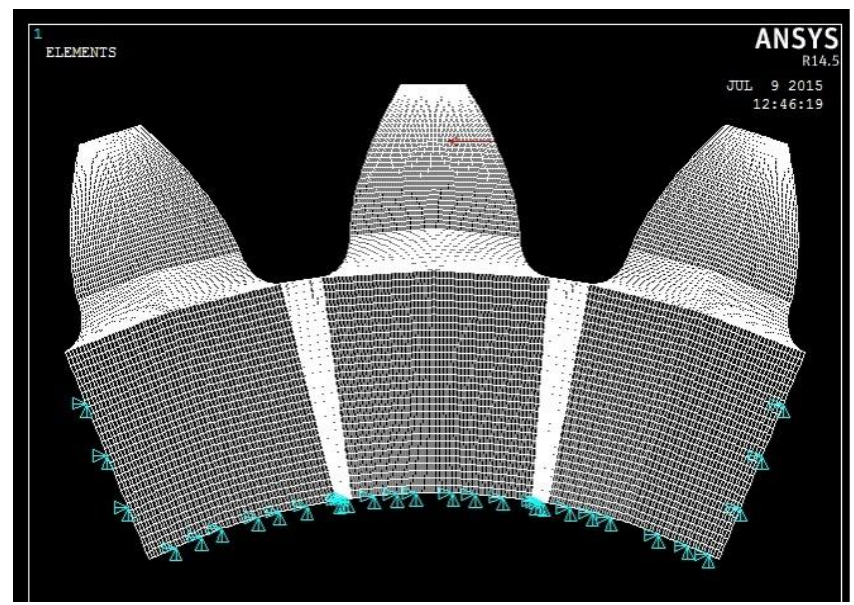

Fig-5: Gear tooth system considered for finite element analysis with suitable boundary conditions

\subsection{Solution Method for 2D Finite Element Method}

In order to solve the system of equilibrium equations, Gauss elimination method is used. The property of symmetry and band form is utilized in the storage of global stiffness matrix. The stress values was calculated for each element using stress-strain relations. The strain-displacement matrix for eight node quadrilateral element is a function of natural coordinates $s$ and $t$ and vary within the element. Hence, stresses evaluated at the Gauss points were found to be accurate. The stress values at nodes are extrapolated from values at Gauss points.

\section{RESULTS AND DISCUSSIONS}

Gear design is a multifaceted process due to the correlation of various parameters. Gear parameter modification should not violate the standards recommended for other parameters. The effect of pressure angle modification on spur gear tooth performance and its dependence on other parameters is stated in the following sections.

\subsection{Effect of Pressure Angle on Critical Section Thickness}

Critical section thickness plays an important gear tooth parameter while evaluating bending stress. It is desirable to have a broader critical section. Figure.6highlights the variation of critical section thickness with the pressure angle. As the pressure angle on the drive side increases, it is seen that tooth thickness at the critical section increases, enhancing the load carrying capacity. The results of critical section thickness obtained are in good agreement with the published results [14].

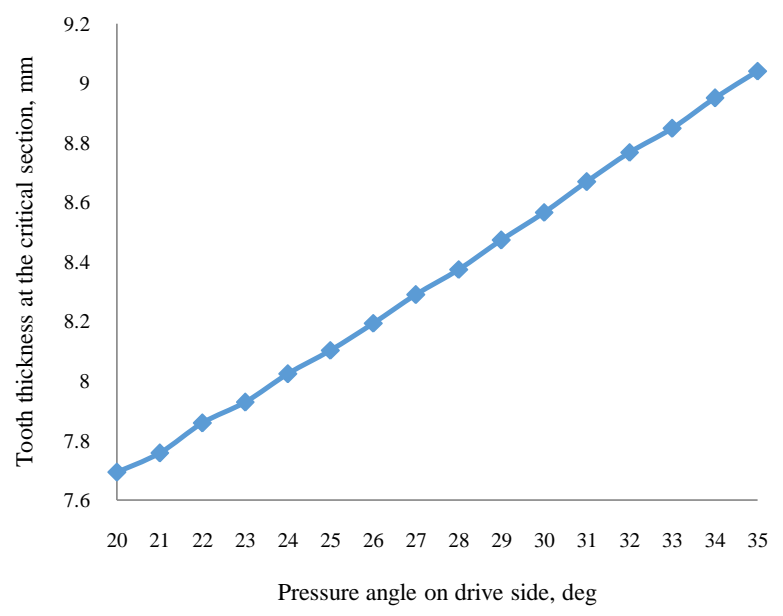

Fig-6: Variation of critical section thickness with pressure angle

\subsection{Effect of Pressure Angle on Tooth Thickness on}

\section{the Addendum Circle}

The tooth thickness on the addendum circle depreciates with increasing pressure angle on drive side. The studies carried out on $6 \mathrm{~mm}$ module gear tooth segment depicted that an increase in the pressure angle is limited to $40^{\circ}$ as the corresponding tooth thickness on the addendum circle becomes 1.2 i.e., $0.2 M_{n}[14]$.

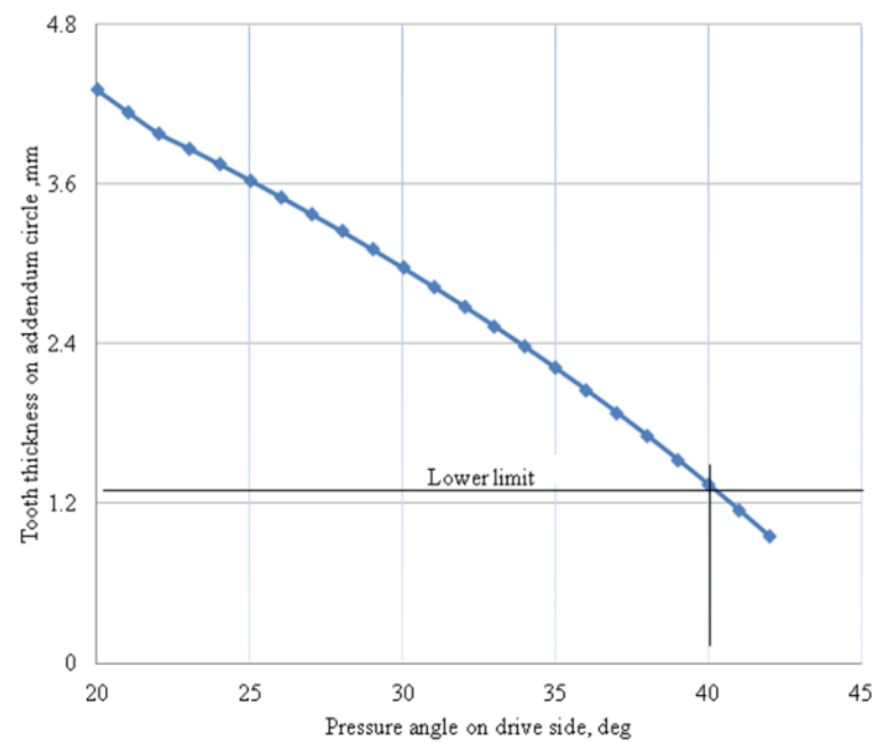

Fig-7: Variation of tooth thickness on addendum circle with pressure angle for $6 \mathrm{~mm}$ module 


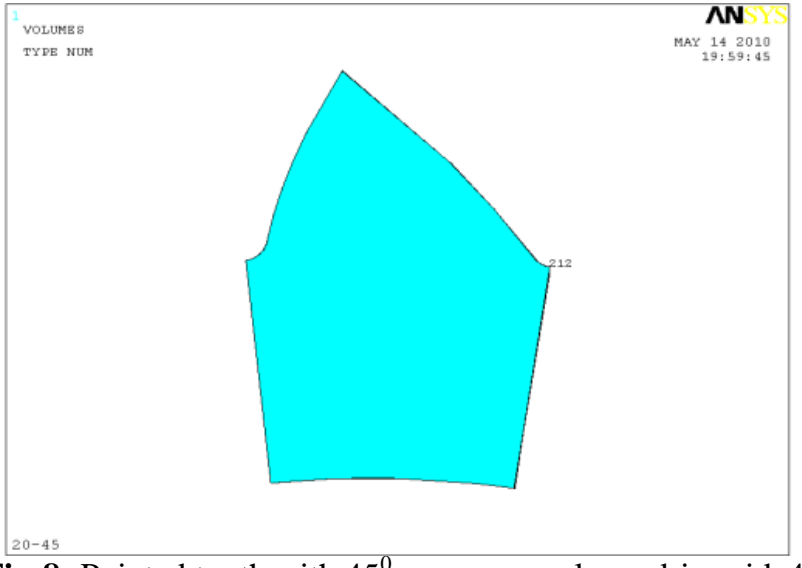

Fig-8: Pointed tooth with $45^{\circ}$ pressure angle on drive side 4 $\mathrm{mm}$ module and zero profile shift.

The studies revealed that the pressure angle modification influences the gear tooth profile whereas the module and number of teeth bear no effect on gear tooth profile. These conclusions come in handy in further assessment of gear tooth stresses.

\subsection{Effect of Pressure Angle on Gear Tooth Stresses}

The stresses in a gear tooth depend primarily on the load and the tooth geometry but there are several other phenomena which must be taken into account. Stress estimation has become important as it has been one of the primary reasons of failure of gears. Studies conducted on gear tooth stress have been discussed in the following sections.

\subsubsection{Effect of Pressure Angle on Bending Stress}

The bending stress is calculated considering the gear tooth as a cantilever beam and is called as static stress which is multiplied by a number of factors to compensate for each of the other influences. Likewise, several methods have been developed in bending stress estimation of symmetric gears. However, in case of asymmetric gears, Tobe's method [11] has proved to be appropriate. Stress calculated using Tobe's method have been compared with 2D FEM results for $M_{n}=$ $4 \mathrm{~mm} ; X=0 ; z_{1}=20$ and $\beta^{\prime}=1.2$.

Table -2: Comparison of bending stresses for different pressure angle

\begin{tabular}{|l|l|l|}
\multicolumn{3}{|c}{ pressure angle } \\
\hline \multirow{2}{*}{ Pressure angle } & \multicolumn{2}{|l|}{ Bending stress, MPa } \\
\cline { 2 - 3 } & Theoretical & FEA \\
\hline $20-20$ & 57.05 & 56.87 \\
\hline $20-21$ & 56.31 & 56.01 \\
\hline $20-22$ & 55.53 & 54.16 \\
\hline $20-23$ & 54.72 & 53.87 \\
\hline $20-24$ & 53.86 & 52.79 \\
\hline $20-25$ & 52.95 & 53.23 \\
\hline $20-26$ & 51.98 & 51.45 \\
\hline $20-27$ & 51.08 & 51.50 \\
\hline $20-28$ & 50.12 & 49.92 \\
\hline $20-29$ & 49.09 & 49.27 \\
\hline $20-30$ & 47.99 & 49.03 \\
\hline $20-31$ & 46.81 & 46.53 \\
\hline
\end{tabular}

\begin{tabular}{|l|l|l|}
\hline $20-32$ & 45.54 & 44.27 \\
\hline $20-33$ & 44.17 & 44.05 \\
\hline $20-34$ & 42.64 & 42.06 \\
\hline $20-35$ & 41.39 & 42.35 \\
\hline
\end{tabular}

It is observed that an increase in pressure angle on drive side is accompanied by a substantial decrease in the bending stress at the critical section. The comparison with Tobe's method showed a variation of $\pm 5 \%$ for $2 \mathrm{D}$ FEM analysis. Thus the FEM analysis is considered suitable for stress estimation and is adopted for further studies. Analysis of symmetric $\left(20^{0} / 20^{0}\right)$ and asymmetric $\left(20^{\circ} / 35^{0}\right)$ spur gears revealed a $25 \%$ stress reduction in asymmetric gears keeping all other parameters same.

\subsubsection{Stress Contours}

From the stress contours, it can be inferred that an increase in pressure angle along the drive side is coupled with the decrease in the bending stress at the critical section for all cases. The overall bending stress induced in case of $20^{\circ} / 32^{\circ}$ pressure angle combination is $45.54 \mathrm{MPa}$. Further increase in the pressure angle results in increase of overall bending stress as the limiting value of tooth thickness on addendum circle is reached at $20^{\circ} / 32^{0}$ Hence, pressure angle modification study is restricted to $32^{\circ}$ on the drive side [15]. A close observation of the above tabulations supports the same.

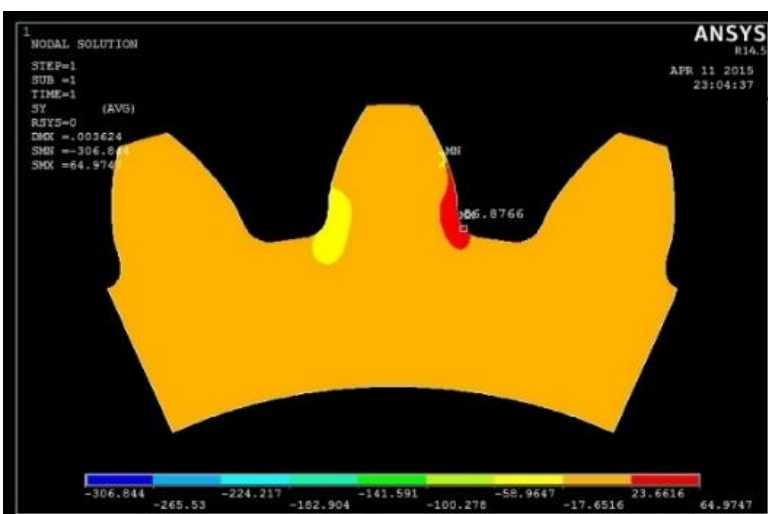

Fig-9: Bending stress contours of $20^{\circ} / 20^{\circ}$ gear teeth segment.

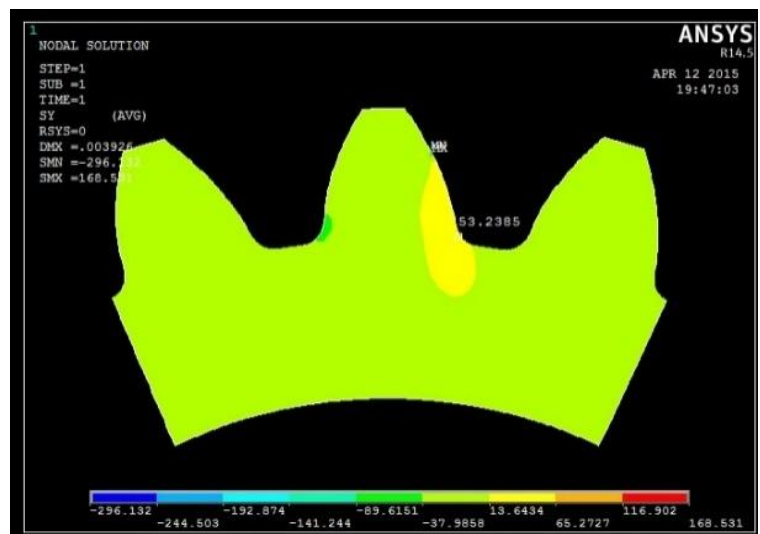

Fig-10: Bending stress contours of $20^{0} / 25^{0}$ gear teeth segment. 


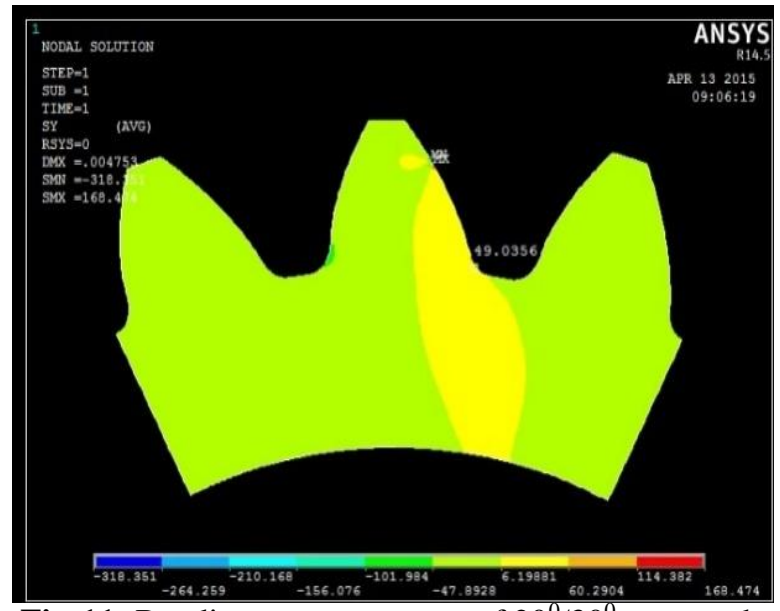

Fig-11: Bending stress contours of $20^{\circ} / 30^{\circ}$ gear teeth segment.

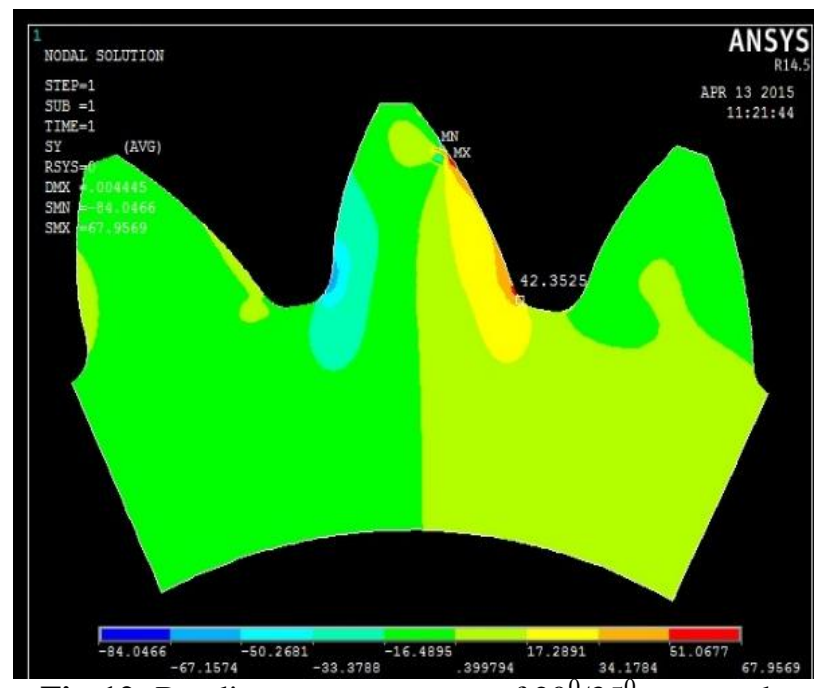

Fig-12: Bending stress contours of $20^{\circ} / 35^{\circ}$ gear teeth segment.

The variation between three teeth segment and full gear body analysis is insignificant as established by the previous works [16]. Hence, three teeth gear segment is considered for analysis to study the effect of loading at HPSTC on adjacent teeth stresses. Stress contours of 2D three teeth gear segments analyses have been plotted for increasing pressure angle on drive side $\left(20^{0}-35^{0}\right)$ as shown in Figures.9-12. The following parameters are considered for the analysis; $M_{n}=4 \mathrm{~mm} ; X=0 ; z_{1}=20 ; z_{2}=30$ and $\beta^{\prime}=1.2$.

\section{CONCLUSION}

The assessment of pressure angle modification on drive side leads to interesting conclusions. While the pressure angle modification affects the gear tooth geometry, the modification study is itself limited by gear parameters like module, number of teeth, contact ratio and profile shift. It has been observed that the pressure angle has insignificant influence on the induced stress whereas the bending stress is considerably reduced by increasing the pressure angle. Following remarks can also be made regarding pressure angle modification.
- With the increase in the pressure angle, gears can be operated with lesser number of teeth compared to AGMA $\quad$ standards $\left(Z_{\min }=\frac{2}{\sin ^{2}\left(20^{0}\right)}=17.097\right)$ since, undercutting is avoided.

- The shape of the tooth becomes more pointed or peaked and the tooth flank becomes more curved.

- Vibration levels saw a significant reduction as a result of low relative sliding velocity and moreover, the wear is reduced.

- The asymmetric tooth geometry allows for an increase in load carrying capacity while reducing the weight and dimensions for gears.

\section{REFERENCES}

[1]. G Mallesh, Dr VB Math, Prabodh Sai Dutt R Ashwij, Rajendra Shanbhag, Effect of Tooth Profile Modification in Asymmetric Spur Gear Tooth Bending Stress by Finite Element Analysis (2009)

[2]. G Mallesh, Math VB Venkatesh, HJ Shankarmurthy, P Prasad Shiva, K Aravinda, Parametric analysis of Asymmetric Spur Gear Tooth (2009)

[3]. G Mallesh, Estimation of Critical Section and Bending Stress Analysis for Asymmetric Spur Gear Tooth.

[4]. G Mallesh, Effect of Rim Thickness on Symmetric and Asymmetric Spur Gear Tooth Bending Stress.

[5]. Pedrero, J.I., Artes M, Approximate equation for the addendum modification factors for tooth gears with balanced specific sliding, Mechanism and Machine Theory, Vol. 31, pp. 925-93,1996

[6]. Thomas J. Dolan and Edward L. Broghamer, A photo elastic study of stresses in gear tooth fillets, University Of Illinois Engineering Experiment Station, Bulletin Series No. 335,1942

[7]. ISO Standard 6336, Calculation of Load Capacity of Spur and Helical Gears

[8]. Huseyin Filiz I, Eyercioglou O. Evaluation of gear tooth stresses by finite element method, ASME,. Journal of Eng. for Industry, Vol.117, pp. 232-219, 1995

[9]. R.Muthukumar and M.R.Raghavan, Estimation of gear tooth deflection by the finite element method, Mech. Mach. Theory Vol. 22, No. 2, pp.181, 1987

[10]. Shuting Li , Finite element analyses for contact strength and bending strength of a pair of spur gears with machining errors, assembly errors and tooth modifications, Mechanism and Machine Theory Vol. 42 , pp.88-114,2007

[11]. Kapelevich, A. L., Geometry and design of involute gears with asymmetric teeth., Mech. Mach. Theory, Vol. 35, pp. 117-130, 2000

[12]. Deng, G., and Tsutomu, Bending load capacity enhancement using an asymmetric tooth profile, JSME International Journal, Series C., Vol.46, No.3, pp.11711177,2003

[13]. Alexander L. Kapelevich ,Direct gear design for optimal gear performance, SME's Gear Processing and Manufacturing Clinic, Oct 6, pp.1-16,2003

[14]. Kadir Cavdar, Fatih Karpat, Fatih C. Babalik., Computer Aided Analysis of Bending Strength of Involute Spur Gears with Asymmetric Profile , Journal of Mechanical Design, Vol. 127, pp.474-484, 2005 
[15]. Fatih Karpat, Stephen Ekwaro, Probabilistic analysis of MEMS asymmetric gear tooth, Journal of Mechanical Design, Vol. 130, pp. (042306-1)-(042306-6), 2008

[16]. M. Celik, Comparison of three teeth and whole body models in spur gear analysis, Mechanism and Machine Theory, Vol.34, pp.1227-1235, 1999

\section{BIOGRAPHIES}

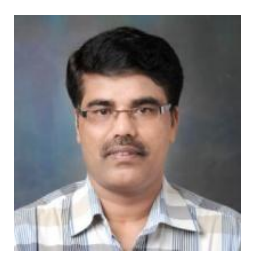

Dr. G Mallesh, Associate Professor, Dept. Of ME, SJCE Mysuru-570006, Karnataka, India

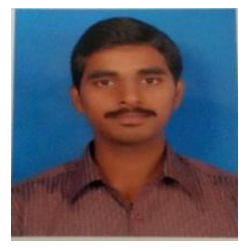

Avinash P, Research Group, Dept. Of ME, SJCE Mysuru-570 006, Karnataka, India

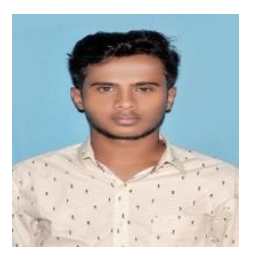

Melvin Kumar R, Research Group, Dept. Of ME, SJCE Mysuru-570 006, Karnataka, India

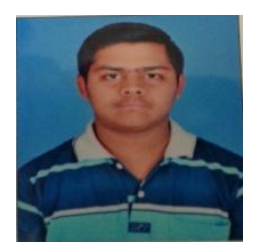

Sacchin G, Research Group, Dept. Of ME, SJCE Mysuru-570 006, Karnataka, India

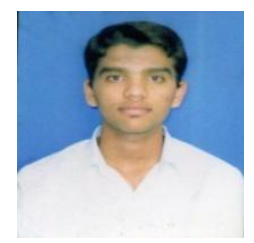

Zayeem Khan, Research Group, Dept. Of ME, SJCE Mysuru-570 006, Karnataka, India 